Three Learning Tasks Delivered to a Wide Range of Student Learning Styles:

What Combination \& Sequence Helped the Students to Understand the Core Material and Fulfil Defined Learning Objectives?

\author{
Rutherford [M.Phil] \\ Programme Leader - BA Advertising \\ University of Chester \\ rutherford@chester.ac.uk
}

\begin{abstract}
In addition to the transferable skills necessary for success in any professional discipline, the study of advertising requires students to develop both Left hemisphere logical/critical skills as well as Right hemisphere spatial/visual skills. This research project exposed students with a wide range of different learning tasks in an effort to determine which tasks (or which combination and sequence of tasks) helped first-year advertising students to understand core material and to fulfil defined Learning Objectives. It was found that the two most significant factors in students' ability to succeed were i) attendance is scheduled sessions and ii), the number of UCAS points with which they were admitted to the programme. These findings are consistent with those reported by Schwartz (2004) that "Prior educational attainment data remains the best single indicator of success at undergraduate level". The implications of the clear link established between students' UCAS points and the ability to fulfil the defined Learning Objectives remains a source of concern for the programme team because, in the past three years (2008-09, 2009-10, and 2010-11) the proportion of students admitted to the programme with the minimum number of UCAS points required for entry has steadily decreased.
\end{abstract}

Keywords: Learning styles, UCAS points, Learning Objectives, cognitive skills 


\section{Project rationale}

Most UK undergraduate Advertising programmes define (and therefore teach) the subject of advertising as either as a sub-discipline of marketing, supplemented by instruction in graphic design, or as a sub-discipline of graphic design, supplemented by instruction in marketing. The former are intended to produce the 'suits' responsible for account and brand management (the roles featured in the television series Mad Men); the latter to prepare 'creatives' who will produce the materials in response to the briefs developed by the former. The BA Advertising programme at the University of Chester takes the position that to oblige applicants to choose between these two 'pathways' is inappropriate for two reasons:

1. 'Suits' need to understand the principles of effective (and affective) visual communication, and 'creatives' need to understand the broader brand and strategy objectives their work is expected to support and advance. Taught in isolation, 'suits' and 'creatives' will not develop sufficient familiarity with the concerns and objectives of the other to be able to collaborate effectively.

2.Applicants cannot be expected to know enough about either of these two 'pathways' or about themselves - to be able to make an informed decision as to which is most appropriate for them.

Accordingly, in place of the 'either-or' approach taken by most other programmes, the Advertising programme at the University of Chester has three core objectives for its students; that they should be:

- competent communications professionals in conscious possession of both the industry specific as well as the transferable skills necessary to achieve a professionally rewarding, intellectually challenging and economically viable self-directed career;

- informed and engaged members of society, able to consider critically the ideological implications of advertising and corporate communications materials and how these shape our personal and social narratives; and,

- reflective, self-aware individuals capable of - and committed to - lifelong learning.

In order to achieve these objectives (and to broaden their professional prospects upon graduation), the Advertising programme at the University of Chester provides students with the 
opportunity to develop skills in both 'pathways'. There is therefore a need to develop an effective teaching, learning and assessment strategy that actively assists students in developing both (Left hemisphere) logical/critical and (Right hemisphere) spatial/visual skills, as well as the transferable skills necessary for the successful pursuit of their professional goals.

Central to our students' ability to achieve these core objectives is their capacity to recognise and to understand the meaning of information. Unfortunately, most students entering the programme do not yet have an adequate ability to:

- recognise the relevant information

- understand the meaning of information, or to

- explain the meaning of information

As Botten and Stent (2003) have observed, if one understands an idea, theory or implication, one can explain it, and, conversely, that if one cannot, one does not ("If you can't explain it simply, you don't understand it well enough" Albert Einstein). While the fact that most students enter the programme without the ability to recognise and express meaning is a serious obstacle, of even greater significance is that their inability to communicate clearly and effectively indicates an insufficiently developed capacity to think with clarity or precision. As Bertrand Russell wrote, "Language serves not only to express thought - but to make possible thoughts which could not exist without it". The cognitive ability required to express and explain ideas in language is therefore a 'meta-skill' - and one without which our students are unable to make appropriate and informed decisions in either the 'strategic' or the 'creative' domain. To assist our students in making informed decision in the conception and design of appropriate materials, it is necessary to identify strategies that will address this shortcoming.

Committed to assisting our students to become effective learners, the programme team undertook a research project in order to assist students to recognise i) the connection between what they 'do' in each module and the broad programme objectives and ii) how each 'atom of knowledge' (a fact, a theory, a strategy, or a technique) enables the construction of a larger 'molecule of understanding'.

In the original design of the BA Advertising programme, a module in Communication was 
incorporated into the curriculum for all Level Four Single Honours students. In the two years prior to this project, it was notes that the Single Honours students consistently performed better than the Combined Honours students (who did not take this module) in the other modules in the programme. In the belief that this difference between the overall levels of achievement was in part a result of the abilities fostered in the Communication module, in the (March 2009) revalidation of the programme, this module was made core for all Level Four students. This module is intended to provide students with a clear understanding of, and an opportunity to improve their skills in, both written and visual communication. In addition to lectures that explain and contextualise these skills, students are required to produce documents that explain the meaning of information to the reader/viewer. The requirement to (attempt to) convey the meaning of information has two immediate and practical advantages:

- $\quad$ such exercises foster the cognitive and critical skills necessary for making informed and appropriate decisions, and

- such exercises provide both staff and students with an accurate means to identify what our students do not yet adequately understand, and so enables us to identify the topic(s) that must be revisited in lectures and/or in seminars.

\section{Objectives of the project}

This experiment was an attempt to identify:

i. Which tasks (or which combination and/or sequence of tasks) were most effective in assisting the first-year students of the undergraduate Advertising programme to develop the ability to understand the core material and fulfil the defined Learning Objectives.

ii. To what extent (if any) did the students' preferred Learning Style (as defined by Honey \& Mumford) influence students' ability to achieve the defined Learning Objectives.

iii. To what extent (if any) did attendance in lectures and seminars influence students' ability to achieve the defined Learning Objectives.

iv. To what extent (if any) students' prior academic achievements (as indicated by UCAS points ${ }^{1}$ ) influenced their ability to achieve the defined Learning Objectives.

1 UCAS (Universities \& Colleges Admissions Service) points are awarded for a range of academic and/or vocational qualifications and are used as in the United Kingdom as an indication of academic achievement to gain entry to higher and further education programmes. When these students applied for entry to the BA Advertising programme, the minimum number of UCAS points required by the university was 240 . 


\section{Description of the project}

During Induction, students were informed that the Communication module is intended to assist them in being able to meet the following three Learning Objectives:

The ability to identify the relevant or essential information (the information to be addressed),

The ability to explain the meaning or implications of information, and

The ability to organise and structure this information to produce a coherent argument,

In addition, students were advised that these skills are essential for their academic, professional and personal development for the following reasons:

1. Both career paths ('suits' and 'creatives') require the ability to recognise the implications of complex data, to make appropriate decisions based on this understanding, and to critically evaluate their work to ensure that it is consistent with the requirements of a brief;

2. The ability to communicate clearly and effectively in language is consistently identified by employers in all sectors as an essential transferable skill - but one that graduates often lack;

3. By bringing vague or erroneous explanations to their conscious attention, the requirement to describe ideas, processes or their consequences in writing provides students with the opportunity to recognise 'holes' in their understanding, and enables them to improve their understanding;

4. The ability to express ideas in language helps us to bring to conscious attention the (often unexamined) assumptions on which our actions are based - thereby rendering us less susceptible to the dangers of logical fallacies;

5. The development of writing skills fosters the capacity for self-reflective thinking, essential for an awareness of how they learn, thus enabling them to become betters lifelong learners; and,

6. Those trained in advertising have (like economists, pollsters, scientists and other 'experts') an important role in educating the public and contributing to an informed debate about the social, cultural and political influence of the commercial visual media, and for which the ability to identify and communicate the meaning of information clearly are necessary prerequisites.

During Induction, the programme's 32 Level Four students completed the Honey and Mumford 
Learning Style questionnaire (1986). "Although there is debate about the validity of the LSQ, its 'test-retest reliability is high." (Coffield et al., 2004) According to the results, (and contrary to what might be expected in an advertising programme), there was not a disproportionate number of 'visual' learners; instead, 'Activist' (16) was the most common learning style identified by the students. 'Reflector' was identified by seven students; 'Pragmatist' and 'Theorist' were identified by five each.

In the module's 24 weekly lectures ${ }^{2}$ attended by all 32 students, the value of effective communications skills was explained and a number of practical strategies were presented, explained and demonstrated. Following the weekly lectures, students attended a one-hour seminar. Prior to the start of the academic year, the programme's 32 Level Four students had been assigned (by the university's Registry Services) to one of three seminar Groups of (approximately) 10 students each. The three members of the programme team each devised three different tasks (A Semantic, B Visual and C Traditional) and over the next 24 weeks, rotated through the hands of all three members of the programme team, spending eight weeks with each, during which, the students completed three tasks for each member of the programme team $(3 \mathrm{x}$ Semantic, 3x Visual and 3x Traditional).

For the first eight weeks of the academic year, Group 1 was exposed to Task Set A, Group 2 to Task Set C, and Group 3 to Task Set B. For the next eight weeks, Group 1 was then exposed to Task Set B, Group 2 to Task Set A, and Group 3 to Task Set C. For the final eight weeks, Group 1 was exposed to Task Set C, Group 2 to Task Set A, and Group 3 to Task Set A. (See Figure 1)

2 The University of Chester operates on a 24-week, single-semester model. 


\section{Weeks 1-8}

Semantic (Group 1)

\section{Weeks 9-16}

Visual (Group 1)

$$
\text { Traditional (Group 2) }
$$

\section{Weeks 17-24}

$$
\text { Traditional (Group 1) }
$$

\section{Visual (Group 3)}

Semantic (Group 2)
Traditional (Group 3)

\section{Visual (Group 2)}

Semantic (Group 3)

Figure 1: the organisation of seminar groups

During each eight-week cycle, students were required to complete three tasks. The students' work was regularly monitored by double-marking to ensure consistency of assessment and to determine the rate of progress of the students in each of the three seminars groups towards the defined objectives.

The students of all three Groups were required to keep a reflective journal throughout the year, in which they were to describe their experiences, including how they defined - and how they attempted to overcome - the challenges set, as well as the evidence for their learning (how they knew that they had achieved the learning they claimed). In these journals, the students were asked to describe:

i. Any problems the student experienced in trying to understand a topic presented in a lecture or seminar (such "problems" are to be described as clearly and as explicitly as possible)

ii. What actions (reviewing their notes, reading a relevant article or chapter from a book, getting feedback from a colleague, going online, meeting with the lecturer, etc.) was found to be most helpful in assisting him/her to resolve this problem - and how/why?

iii. What s/he discovered about his/her approach to learning as a result of this experience? (For example, did the most successful method depend on the kind of problem?) 
In each journal entry, students were required to make reference to their preferred Learning Style (based on the results of the Honey \& Mumford questionnaire completed during Induction week prior to the beginning of taught sessions) and to their Personal Metaphors for Learning.

As identified by Goldfinch and Hughes (2007), the members of the programme team were aware that any intervention must acknowledge the widespread phenomenon of students' overconfidence in their communication skills and, in a supportive environment, provide students with a more realistic sense of their actual standard in order to avoid undermining their self-esteem. Accordingly, in order to provide a positive and supportive learning environment, in the feedback provided, the programme team undertook to recognise the students' efforts and to offer encouragement, and to ensure that, where critical feedback was deemed appropriate, this was expressed with sensitivity and due tact. Students were also advised that their comments as peer reviewers must adhere to these same principles.

Finally, it was recognised that the learning environment would be influenced by the different teaching styles and relationships developed by each member of the programme team. In an effort to identify how these influenced the students' learning experience, at the end of each of the three cycles of this project, students were asked to prepare a reflective commentary on the previous eight weeks, describing the learning environment, and to reflect critically on how this environment influenced their approach to the material and to the tasks set.

\section{Methodology}

\section{Task Set A (Semantic):}

Students in this group were assigned to write three brief documents (a memo, a summaries and the outline for an essay) in which they were expected to identify, explain and organise the relevant information to make its meaning and inter-relationship apparent to a general reader who knows nothing beyond what is explained in the text submitted. Students were given detailed, 'line-by-line' logical/critical feedback from both the seminar leader and from their peers (via online discussion boards) on the extent to which their work fulfilled the three objectives.

\section{Task A1}

Students were assigned to produce a business memo identifying and summarising the key points of a recent lecture in the core advertising theory module. Students were then required to peer 
review (examine and comment on) the work of another (whose identity was not known to the reviewer) in terms of the clarity with which the information was presented. Following this feedback, both students (author and peer-reviewer) then received detailed written feedback on: i) the accuracy with which the key points were identified and ii) the accuracy and clarity with which this information was explained.

Task A2

Students were assigned to read an essay on the relationship between language and meaning (Orwell's Politics and the English Language) and to critically analyse this, with explicit reference to:

- the essential information (What is the writer trying to say?)

- the meaning of the text (Why does the writer want you to know this?) and

- the strategies and/or techniques (including the organisational structure in which the information is provided) employed by the writer to convey his/her meaning.

Students were then required to peer review (examine and comment on) the work of another (whose identity was not known to the reviewer) in terms of the clarity with which the information was presented. Following this feedback, both students (author and peer-reviewer) then received detailed written feedback on: i) the accuracy with which the key points were identified and ii) the accuracy and clarity with which this information was explained.

\section{Task A3}

In preparation for the Final Essay to be submitted at the end of this module, students were required to prepare a detailed schematic outline of their essay, demonstrating their ability to:

- identify (by the proposed headings to be used in this essay) the essential information to be addressed (the topics, or 'atoms of information' that must be included),

- explain (by the proposed subheadings to be used in this essay) the meaning or implications of the information to be addressed (what they propose to say about each topic), and

- organise and sequence their proposed headings and subheadings under which they propose to provide this information in order to produce a coherent presentation of the subject. 
Students were then required to peer review (examine and comment on) the work of another (whose identity was not known to the reviewer) in terms of the clarity with which the information was presented. Following this feedback, both students (author and peer-reviewer) then received detailed written feedback on: i) the accuracy with which the key points were identified and ii) the accuracy and clarity with which this information was explained.

\section{Task Set B (Visual):}

Students in this group were assigned to examine and then to produce three illustrated texts from a variety of disciplines (not restricted to advertising), which use visual design (illustrations and page layout) to enhance the reader's understanding of the essential information. Following the submission of each Task, students were given formative feedback from both the seminar leader and their peers on the extent to which their work fulfilled the three defined Learning Objectives.

\section{Task B1}

Students were assigned to create an illustrated magazine article to communicate the essential information derived from one of these texts. Each student created an alternative magazine layout for one of the articles, including the selection of appropriate images and incorporating them into the page in an appropriate manner. This task required students to recognise, understand and integrate the meaning of information derived from various sources.

Each member of these focus groups was then assigned to read one of the layouts produced by one of the other subgroups. Students were then given a generic questionnaire which asked them to identify the key information in the text and indicate the clarity with which the layout presented this. (Questions included: What were the three main facts that the article communicated? How clear was the text? To what extent did the images help with your understanding of the text?)

\section{Task B2}

The focus group then prepared a brief presentation using any combination of Video, Physical Artefacts, Whiteboard, OHP, Role Play and/or Demonstration, and Audience participation to communicate the contents and meaning of one of the articles to the entire seminar Group.

\section{Task B3}

Students were asked to select one of the presentations and write a 250-word essay to determine 
the extent to which their peer has i) demonstrated knowledge of the essential information conveyed in the article and, ii) conveyed his/her understanding of the principles of effective communication this Task has attempted to foster through the different stages. Students received feedback on these essays.

\section{Task Set C (Traditional Academic):}

Students in this seminar group were required to read and consider a number of selected texts of $20^{\text {th }}$ century expository prose drawn from the Western literary canon, all of which were chosen according to their ability to model a high standard for the effective use of language and rhetoric to convey information and meaning. Students were then required to prepare and submit three 250word essays (Tasks C 1-3) based on these readings. Students were given feedback indicating the extent to which they had met the three defined Learning Objectives.

To assess the degree of the students' progress (if any) towards the three module objectives, the work submitted for all three tasks in all three Groups was jointly assessed by all three members of the programme team at the end of each eight week cycle and the students' reflective commentaries read and considered carefully.

\section{Results and findings}

The graphs in the following section indicate the level of achievement for each student (identified on the $\mathrm{X}$ axis by their number in the Group) based on an average of their assessed marks on the three tasks set in each seminar cycle. Following each Performance graph are two others: the first indicates the attendance of the students in within each Group at the 24 sessions, and the second, the UCAS points of the students in each Group.

Group 1: For the first eight week cycle of the project (weeks 1-8), Group 1 was assigned to complete the three Tasks A (Semantic); for the next eight weeks (weeks 9-16), Group 1 was assigned to complete the three Tasks B (Visual); for the final eight weeks (weeks 17-24), Group 1 was assigned to complete the three Tasks C (Traditional). The progress of Group 1 is diagrammed in Figure 2. 


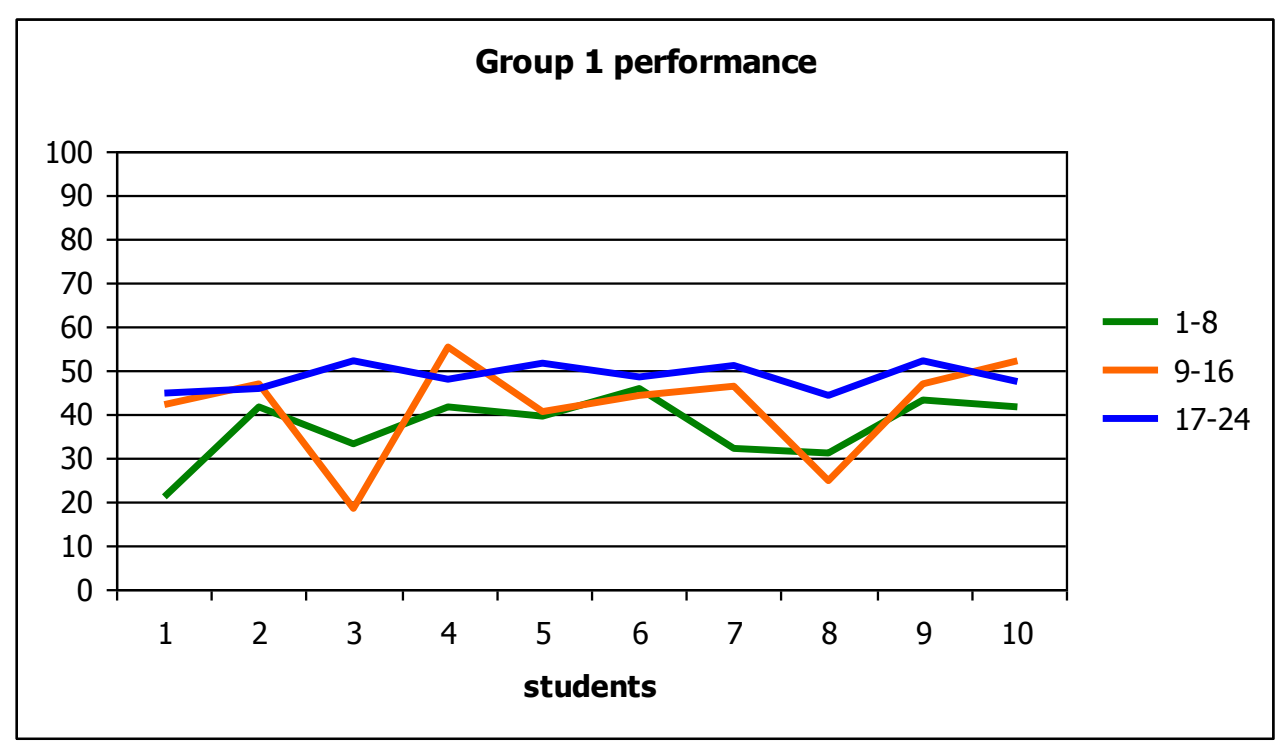

Figure 2: the performance of Group 1

It can be observed that, in the first two cycles (Semantic and Visual), this group performed poorly, but by the third cycle (Traditional), had achieved a notable improvement.

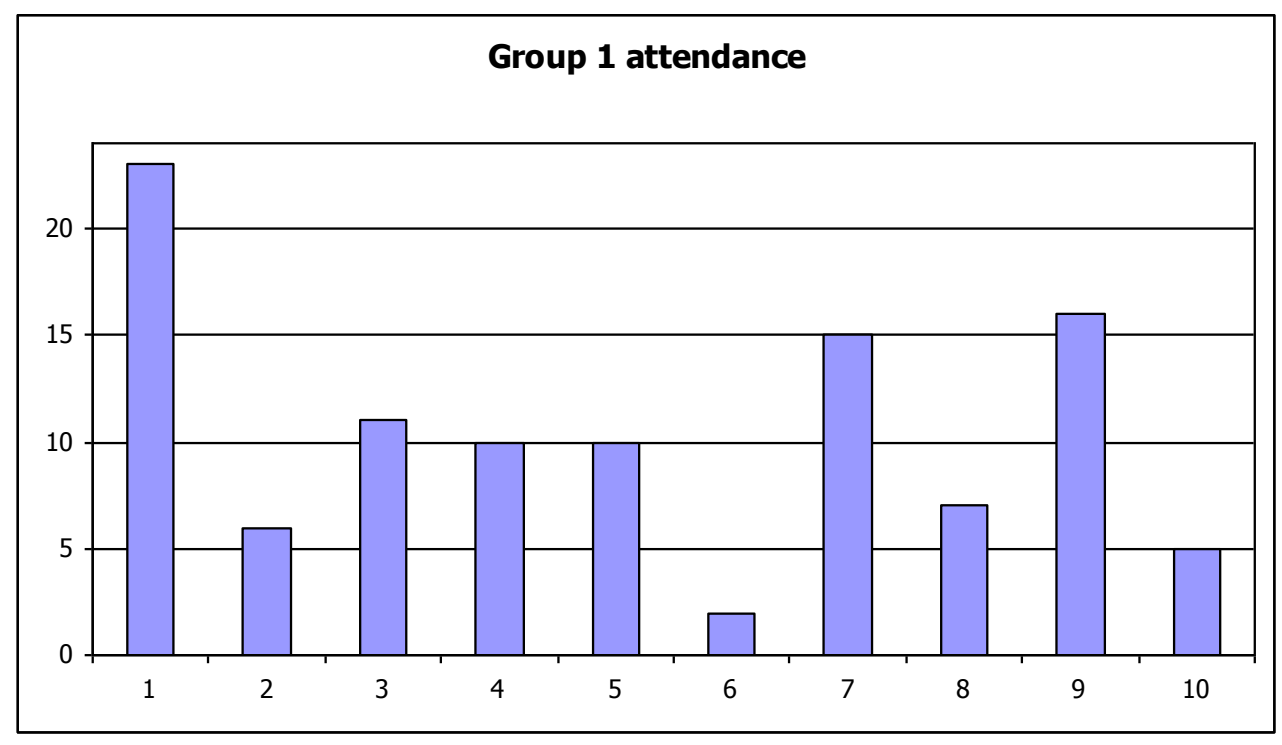

Figure 2a: Group 1 attendance at sessions 


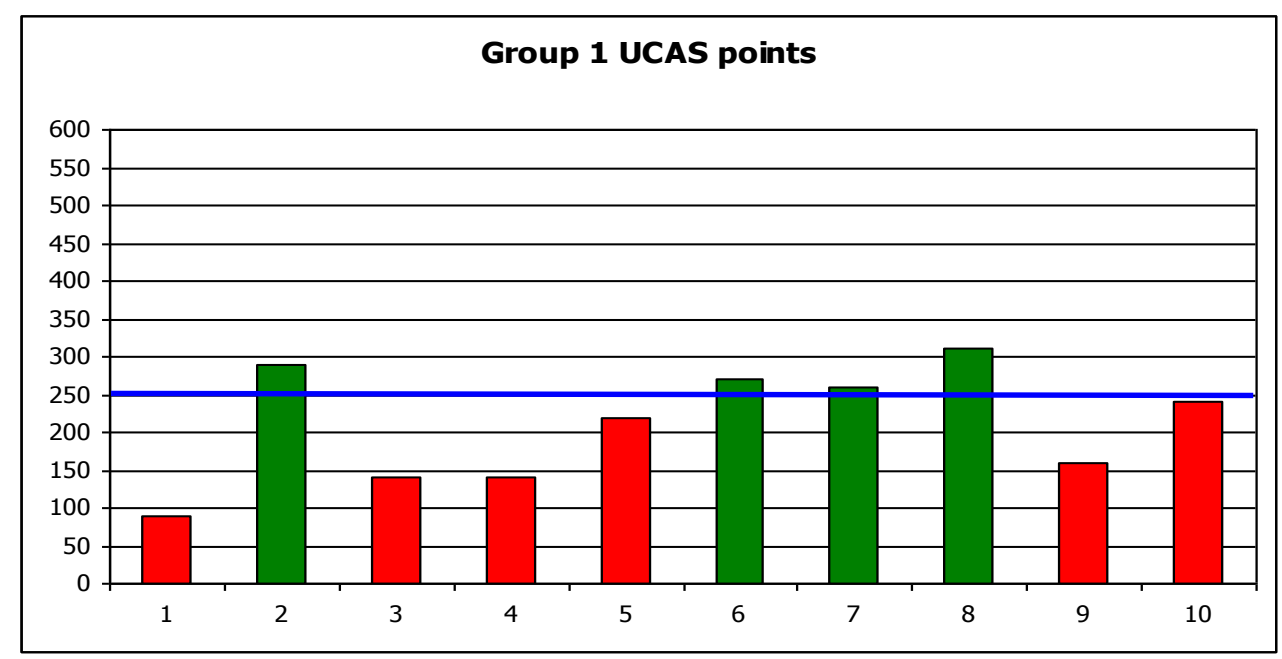

Figure 2b: Group 1 UCAS points

Group 2: For the first eight week cycle of the project (weeks 1-8), Group 2 was assigned to complete the three Tasks C (Traditional); for the next eight weeks (weeks 9-16), Group 2 was assigned to complete the three Tasks A (Semantic); for the final eight weeks (weeks 17-24), Group 2 was assigned to complete the three Tasks B (Visual). The progress of Group 2 is diagrammed in Figure 3: the performance of Group 2

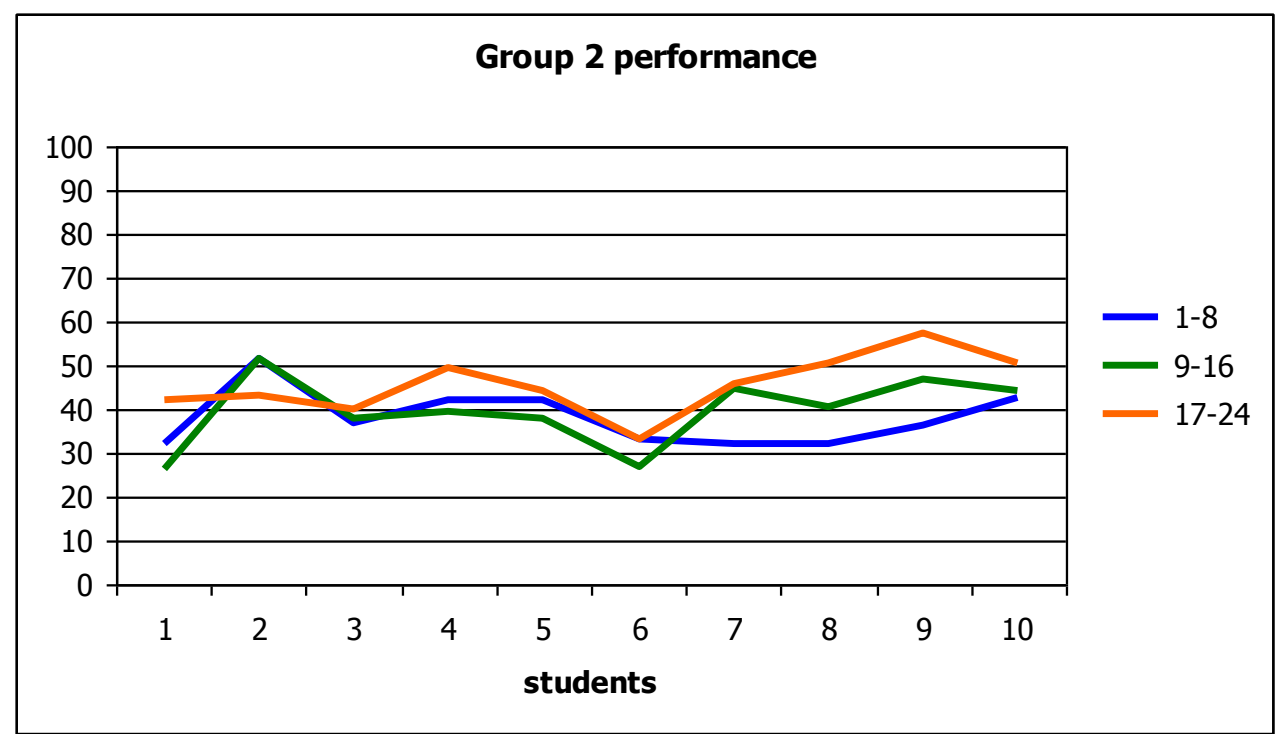

It can be observed that, in the first (Traditional) and second (Semantic) cycles, this group achieved unsatisfactory results, but that there was a notable improvement in the third (Visual) cycle. 


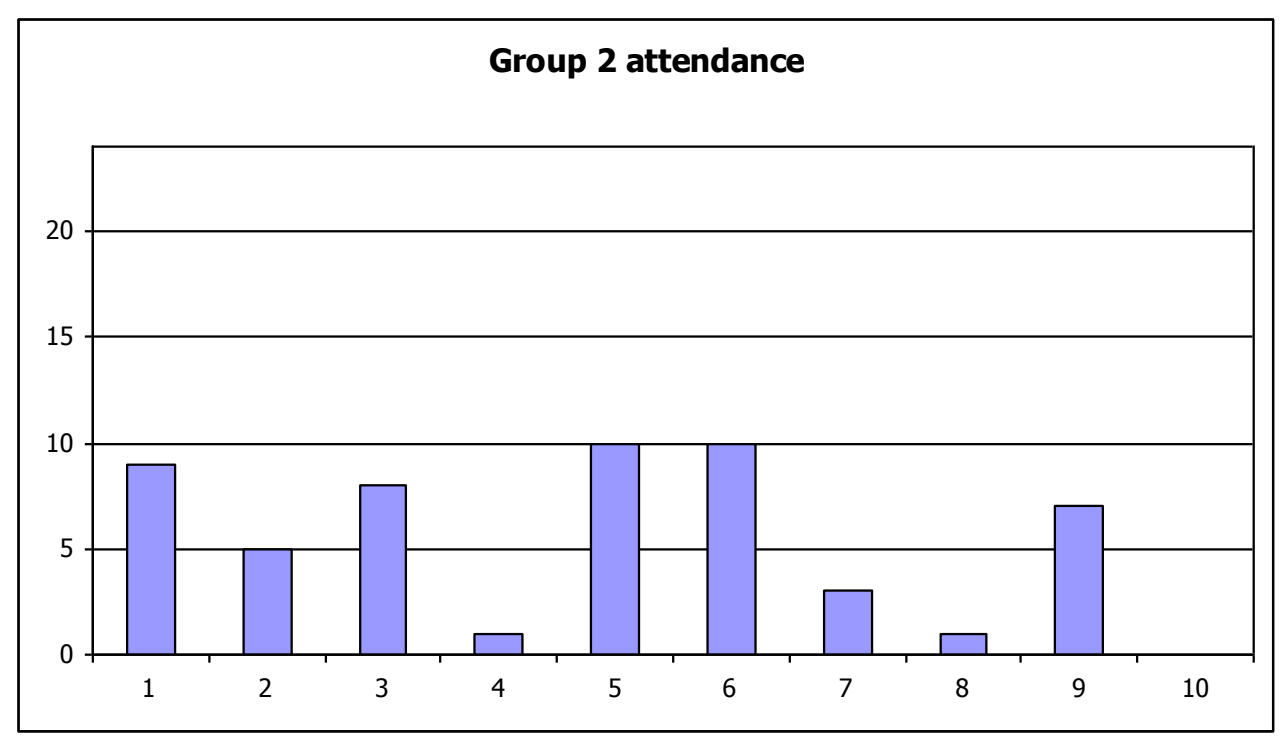

Figure 3a: Group 2 attendance at sessions

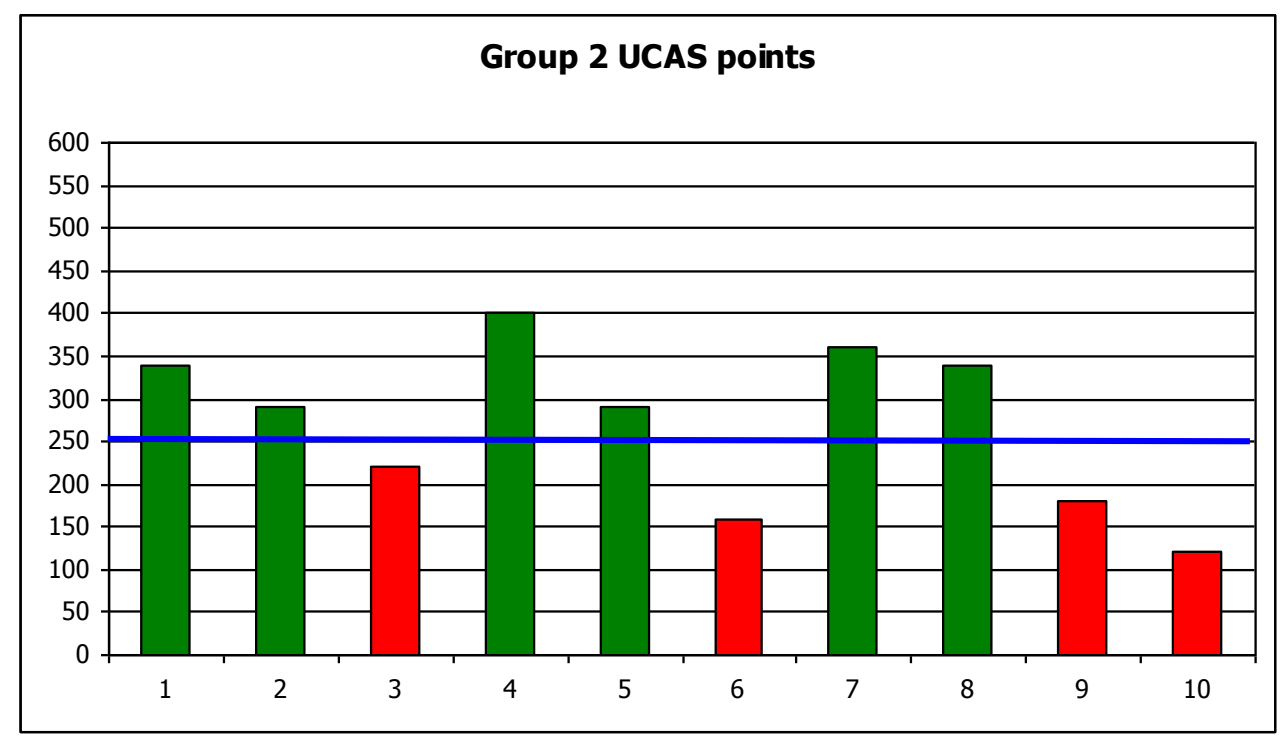

Figure 3b: Group 2 UCAS points

Group 3: For the first eight week cycle of the project (weeks 1-8), Group 3 was assigned to complete the three Tasks B (Visual); for the next eight weeks (weeks 9-16), Group 3 was assigned to complete the three Tasks C (Traditional); for the final eight weeks (weeks 1724), Group 3 was assigned to complete the three Tasks A (Semantic). The progress of Group 3 is diagrammed in Figure 4. 


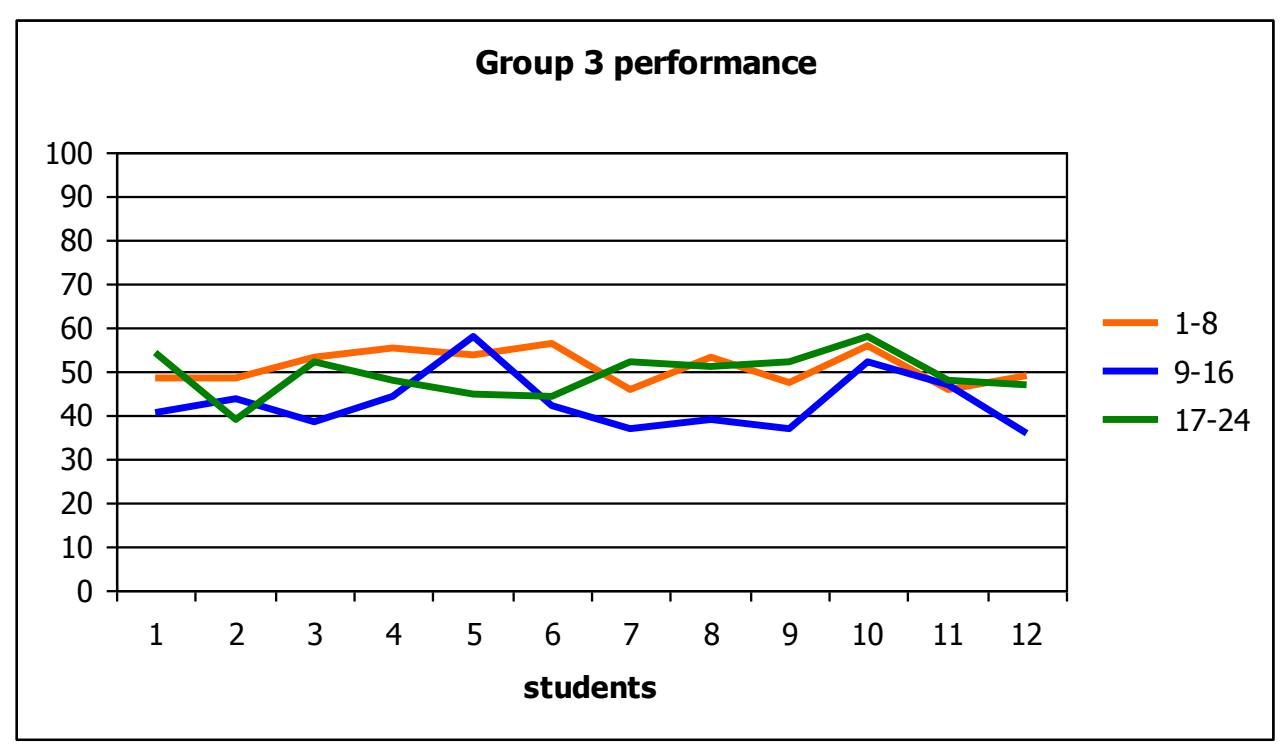

Figure 4: the performance of Group 3

The results achieved by the students in Group 3 clearly indicate the effect of a wide range of preferred learning styles; where some students (\#1-6) were clearly comfortable with visual design tasks, and some (\#5 and 10) with the demands of traditional academic tasks, and some (\#7-10) showed the ability to pursue and explain meaning in the Semantic tasks.

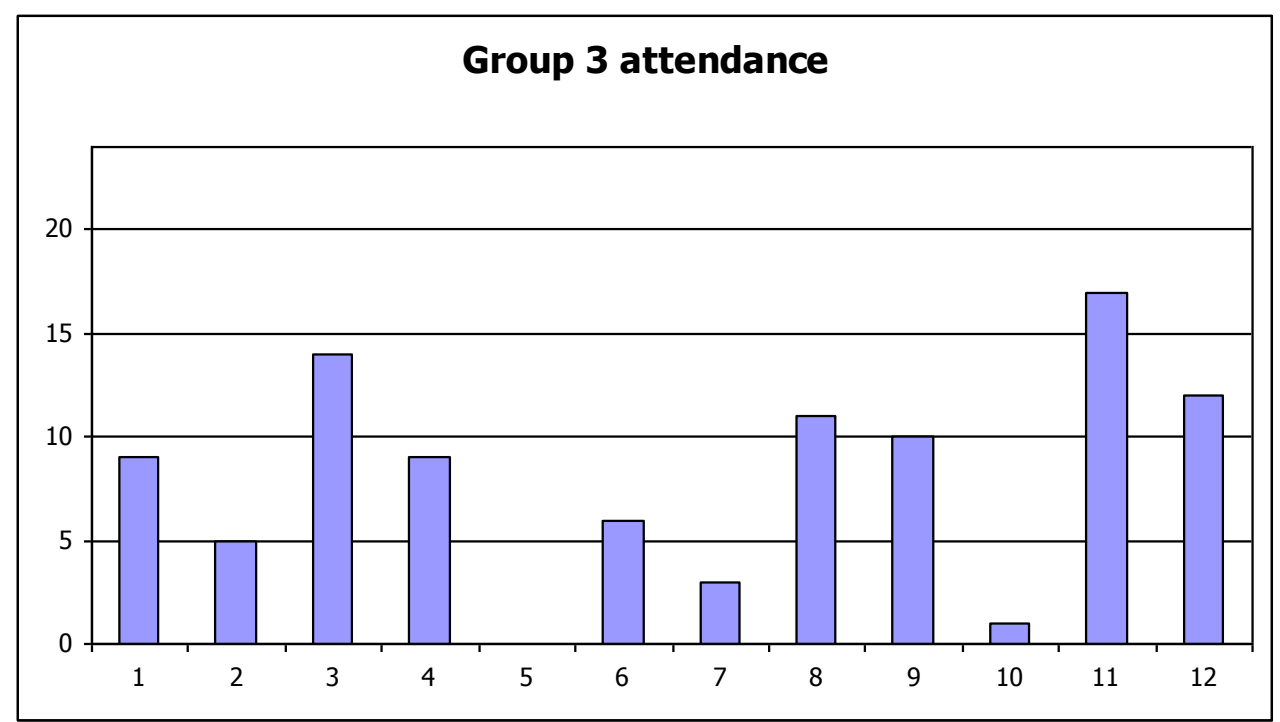

Figure 4a: Group 3 attendance at sessions 


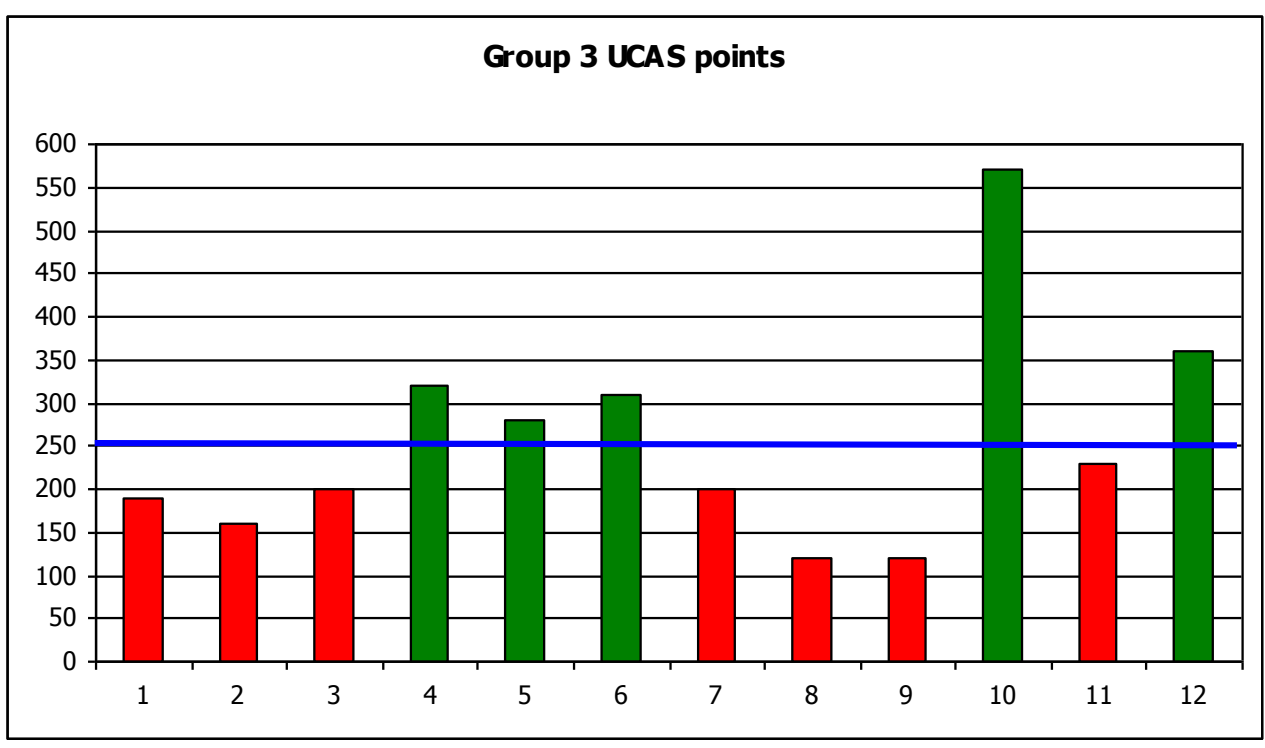

Figure 4b: Group 3 UCAS points

Overall however, (based on average marks of the three Groups), the level of achievement of the students was disappointing. Figure 5 compares the results of the three groups over the duration of the 24 week project.

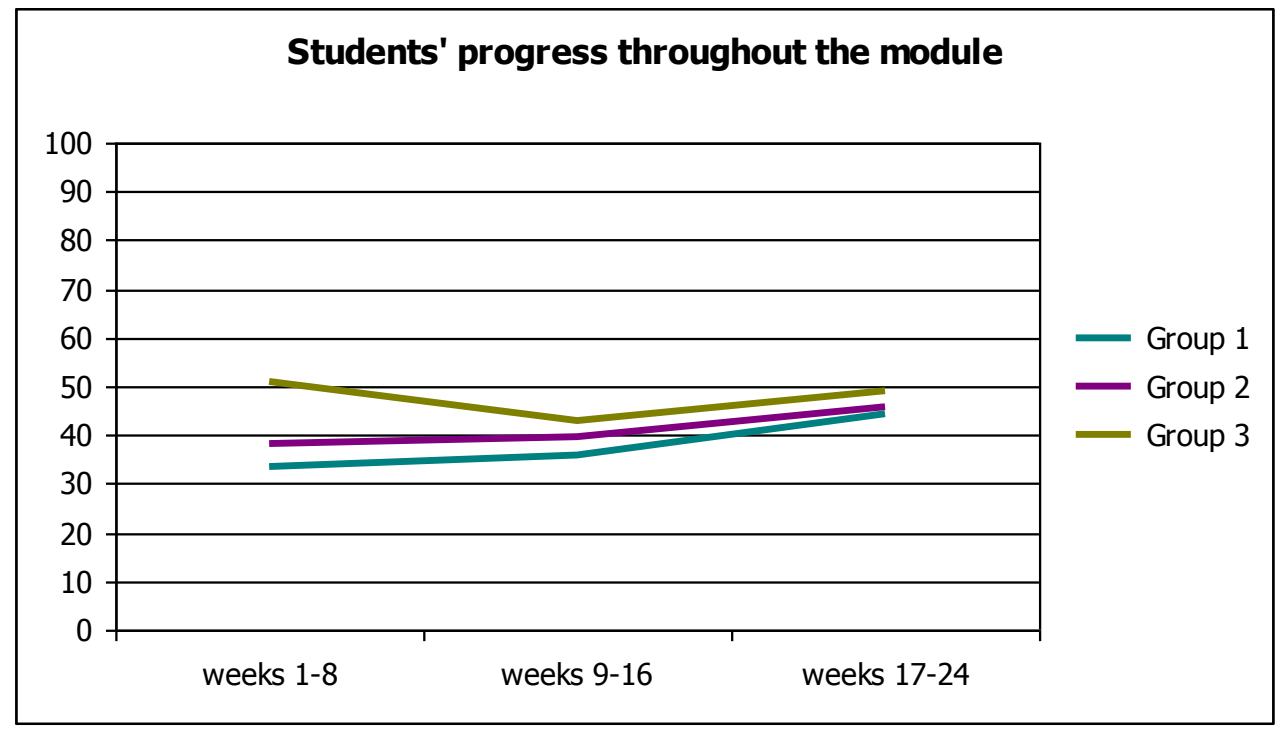

Figure 5: the progress of all Groups over the duration of the project

Reviewing the results of the project, it can be seen that:

In response to the question as to which tasks (or which combination and/or sequence of tasks) were most effective in assisting the students to develop the ability to understand the core material 
and fulfil the defined Learning Objectives, it is apparent that, despite the initial differences in their degree of success in achieving the defined Learning Objectives during the first eight week cycle, by the end of the project, all three Groups had achieved similar results. This would suggest that the sequence in which the students encountered the three Task sets had no discernible impact on the students' ability to achieve the defined Learning Objectives by the end of the year.

- The greatest increase in the ability of students to achieve the defined Learning Objectives was in Group 1: from an average of $34 \%$ in the first cycle, to $36 \%$ in the second, and $44 \%$ in the third - an increase of $10 \%$. This increase is particularly notable because the students in Group 1 had an average of only 197 UCAS points - indicating that this Group began the year with a significantly lower level of prior academic achievement than those in the other two Groups. That they nevertheless achieved approximately the same over level marks therefore represents a greater degree of progress than that achieved by the other two Groups.

- There was a similar degree (8\%) of improvement in the ability of the students in Group 2 to achieve the defined Learning Objectives: from an average of $38 \%$ in the first cycle, to $40 \%$ in the second, and $46 \%$ in the third. The students in Group 2 had an average of 270 UCAS points.

- There was a small decrease of $2 \%$ in the ability of the students in Group 3 to achieve the defined Learning Objectives: from an average of $51 \%$ in the first cycle, dipping temporarily to $43 \%$ in the second, but increased to $49 \%$ in the third. The students in Group 3 had an average of 255 UCAS points.

- Although a small minority of the students who had identified themselves as 'Activists' performed well above average in the tasks set in all three Groups, the majority of students who had identified themselves as 'Activists' performed at or below the average.

- One of the seven students identified as a 'Reflector' performed very well in all Tasks, however the other six 'Reflectors' performed poorly overall.

- All five students identified as a 'Theorists' achieved above average in all Tasks. 
- All five students identified as a 'Pragmatists' achieved above average in all Tasks.

While the programme team was disappointed by both the overall levels of achievement and the degree of improvement demonstrated by most students, it appears that the high level of absences were indeed a significant factor in the results achieved. Of the 33 students in the module, 19 were absent from six or more of the scheduled lectures and seminars. This belief is supported by the broad correlation between attendance and performance (those students with better attendance generally achieved better results, while those who attendance was poor generally achieved lower results).

In addition, in the reflective commentaries submitted at the end of each of the three eight-week cycles of this project, (in which students were asked to describe this environment, and to reflect critically on how this environment influenced their approach to the material and to the tasks set), a common complaint offered by students in all three Groups was that the number of submissions required (three tasks plus a reflective commentary) and frequency (one every two weeks) resulted in a disinclination to invest a significant amount of time and effort in these, but to simply "throw something together" in time to meet the deadline.

The most significant and consistent relationship identified was that between UCAS points and performance. Overall, those students with 260 or more UCAS points upon entry to the programme performed demonstrably better in all Tasks, while those with 230 - 270 points (close to the university's required minimum of 24-260 points) achieved results in the middle, or average band, although it is noted that their levels of achievement were not as consistent as those with higher UCAS scores. As could be expected, those who had been admitted to the programme with substantially fewer UCAS points than the university's required minimum of 24-260 points were generally unable to fulfil the defined Learning Objectives in any of the tasks in any of the three Groups.

\section{Conclusions}

Based on the analysis of these results, it was decided to maintain all three types of Tasks for the following academic year. In order to address the complaint expressed by students (that the number of submissions discouraged them from investing a significant amount of time and effort), 
the total number was reduced from nine to four. Further, it was decided that students would be offered the opportunity to submit these for formative feedback, based which, they would be provided with sufficient time to revise these in accordance with the feedback received prior to their submission for sumative assessment.

In regards to the poor levels of attendance, there is a serious, and growing problem in many HE and FE institutions with students' lack of adequate engagement with the learning environment. In an effort to identify strategies to address and mitigate this, the lead investigator has begun to develop a subsequent research project that will investigate the relationship between students' 'metaphors for learning' (how they 'mentally picture' education) and the extent to which students actively engage in the learning process (For a more comprehensive explanation of this issue, the reader is referred to Rutherford, 2011).

The implications of the clear link established between students' UCAS points and the ability to fulfil the defined Learning Objectives remains a source of concern for the programme team. These findings are consistent with those reported by Schwartz (2004) that "Prior educational attainment data remains the best single indicator of success at undergraduate level". As indicated in Figure 6, in the past three academic years (2008-09, 2009-10, and 2010-11) it has been discovered that the proportion of students who have been admitted to the programme with the minimum number of UCAS points established by the university (240) has steadily decreased.

The programme team have no control over admissions.

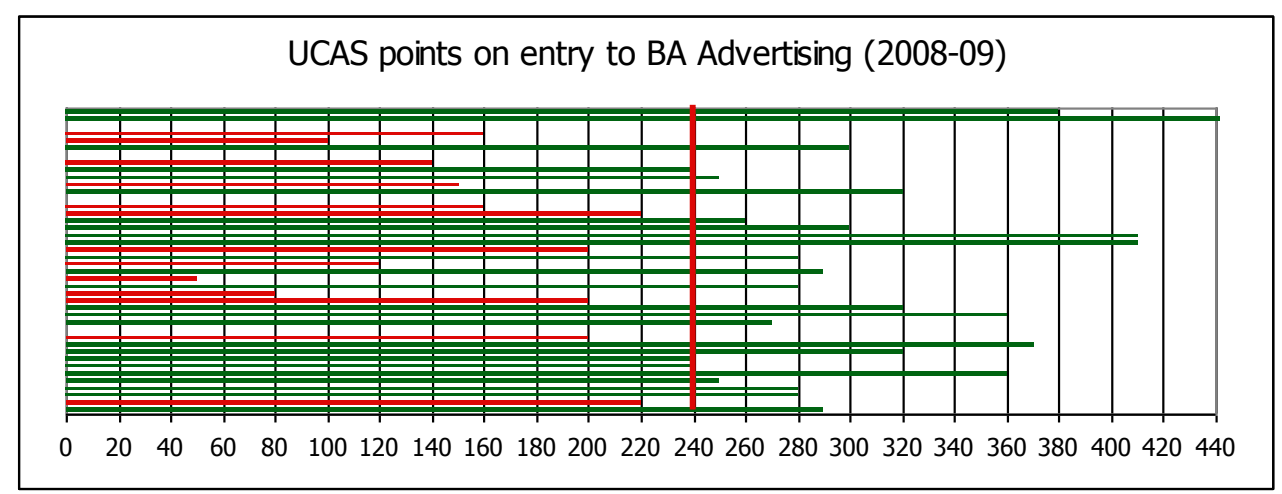



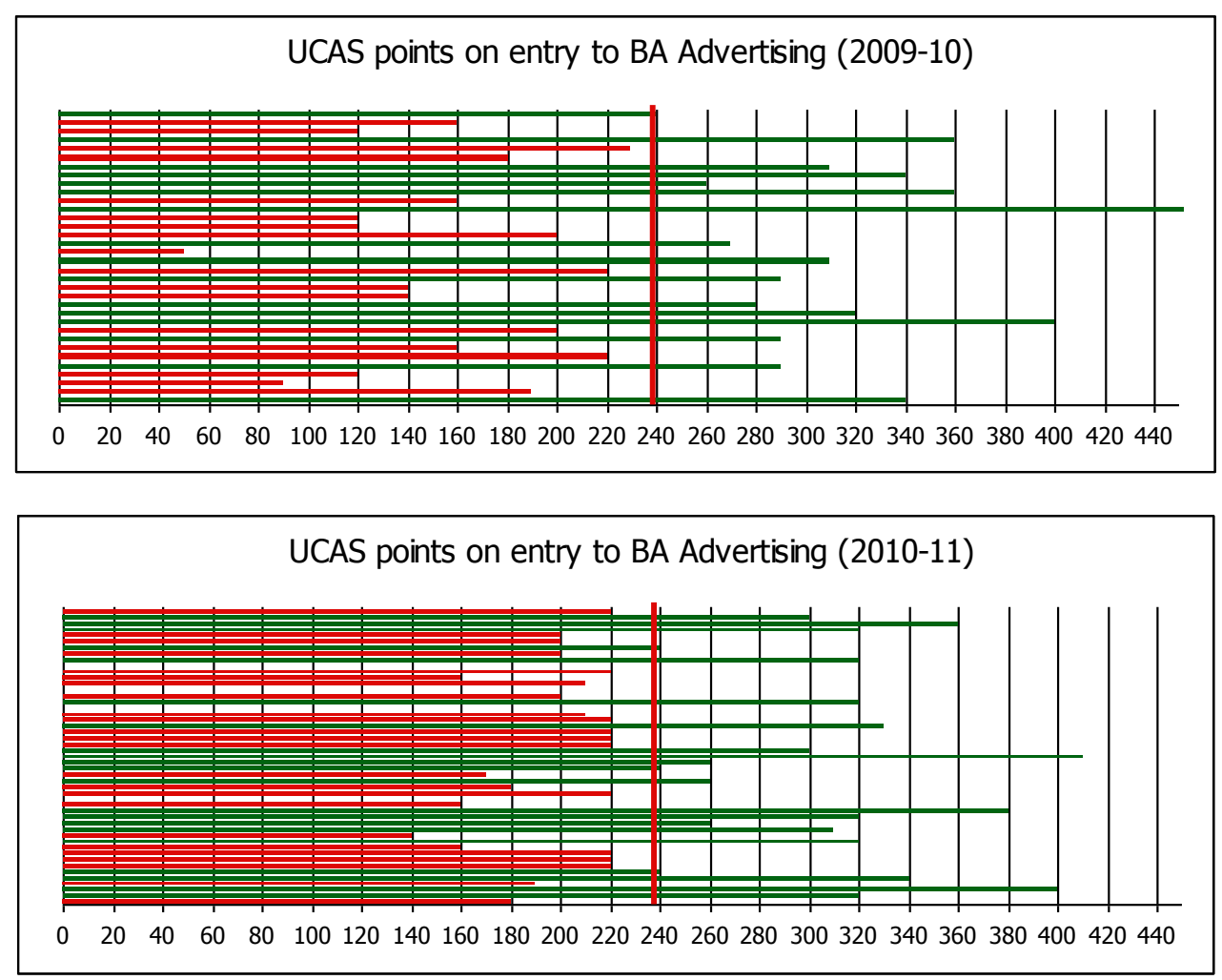

Figure 6: The UCAS points of students admitted to the BA Advertising programme since 2008

As universities come under increasing pressure to expand enrolment in order to offset the reduction in government funding, this is certain to become an ever-more significant issue in years to come.

In addition to the weaker academic skills and inclinations of many of those entering university, those of use who design higher education programmes must now also contend with the pressure exerted by government and university administrators to ensure that Learning Objectives as well as the criteria by which their attainment is measured defer to the now-dominant metaphor of The Market as the ultimate arbiter of both purpose and value (Newman and Courturier, 2002). Whereas the value or 'quality' of HE programmes had previously been defined and maintained by a rigorous process of peer review (Clark, 1983), their 'quality' is now assessed according to two very different criteria: the unit cost at which large numbers of students can be successfully promoted ('processed') through programmes of study ('state quality'), and the popularity of programmes as indicated by consumer choice ('market quality') (Barnett, 1992). Furthermore, the difficulty in engaging students in the pursuit of the higher cognitive skills deemed essential by industry is exacerbated by an institutional culture that, increasingly by design and decree, gives 
primacy to those skills traditionally learned by 'watching and doing' - leading a significant proportion of students to misunderstand both the nature of these higher level skills as well as how they are attained.

With thanks to Christian Okeke and Tinuke Lawal for assistance with data analysis. 


\section{References}

Barnett, R. (1992). Improving Higher Education. Buckingham: SRHE and Open University Press.

Botten, S., Stent, L., (2003) Learning Through Innovation, (http://learningwithsouthglos.org.uk/LTI/project/projectschools/primary/wheatfieldprimar y/index.htm)

Clark, B. (1983). The Higher Education System: academic organization in cross-national perspective. London: University of California Press.

Coffield, Moseley, Hall, Ecclestone, (2004) Should we be using learning styles?: What research has to say to practice. Learning and Skills Research Centre, London, England.

Gardner, H., (1993) Frames of Mind, the theory of multiple intelligences. Fontana Press, London

Goldfinch, J and Hughes. M., (2007) Skills, learning styles and success of first-year undergraduates: 8; Active Learning in Higher Education, HEA/SAGE

Newman, F. and Courturier, L. (2002). Trading Public Good in the Higher Education Market. London: Observatory on Borderless Higher Education

Pitts, S.E., (2005) 'Testing, testing... ': How do students use written feedback?: 6; Active Learning in Higher Education, HEA/SAGE

Race, P., (2001) A Briefing on Self, Peer and Group Assessment. York: Learning and Teaching Support Network

Rutherford, (2011). Mental Pictures and their implications for Higher Education. Networks HEA Art Design Media Subject Centre (Issue 12), Brighton, UK

Schwartz, S. (2004). Fair admissions to higher education: recommendations for good practice. Admissions to Higher Education Steering Group. BIS

Tavris, C., Aronson, E., (2007) Mistakes Were Made (but not by me): Harcourt, Orlando University of Chester, (1999) Learning Teaching and Assessment Strategy:

Zwanenberg, N., Wilkinson, L. J., Anderson, A. (2000) Felder and Silverman's Index of Learning Styles and Honey and Mumford's Learning Styles Questionnaire: how do they compare and do they predict academic performance?: Educational Psychology, Vol. 20, No.3, p365-380. 